\title{
Calibration Strategies Applied to Laser-Induced Breakdown Spectroscopy: A Critical Review of Advances and Challenges
}

\author{
Vinicius C. Costa, ${ }^{a}$ Diego V. Babos, ${ }^{b}$ Jeyne P. Castro, ${ }^{b}$ Daniel F. Andrade, ${ }^{b}$ \\ Raimundo R. Gamela, ${ }^{b}$ Raquel C. Machado, ${ }^{\circ b}$ Marco A. Sperança, ${ }^{c}$ \\ Alisson S. Araújo, ${ }^{b}$ José A. Garcia ${ }^{b}$ and Edenir R. Pereira-Filho ${ }^{\circledR} * b$ \\ ${ }^{a}$ Laboratório de Espectrometria Atômica (LEA)/LabPetro, Departamento de Química, \\ Universidade Federal do Espírito Santo, 29075-910 Vitória-ES, Brazil \\ ${ }^{b}$ Grupo de Análise Instrumental Aplicada, Departamento de Química, \\ Universidade Federal de São Carlos, 13565-905 São Carlos-SP, Brazil
}

${ }^{c}$ Grupo de Abordagens Analíticas Alternativas (GAAA), Instituto de Pesquisa em Bioenergia (IPBEN), Instituto de Química, Universidade Estadual Paulista (Unesp), 14800-060 Araraquara-SP, Brazil

\begin{abstract}
Over the years, laser-induced breakdown spectroscopy (LIBS) has been reported in the literature as an alternative to traditional methods of analysis, becoming well established among spectroanalytical techniques. LIBS is a technique widely used for qualitative approaches; however, it is necessary considerable effort for use in quantitative analysis, mainly due to severe matrix effects. These limitations make it difficult to broaden the application of LIBS in quantitative analysis. In this sense, this review discusses recent advances in calibration strategies applied in LIBS for minimizing matrix effects and enabling determination with satisfactory accuracy and precision. Applications, advantages, and limitations of the calibration strategies, such as matrix-matching calibration (MMC), internal standardization (IS), standard addition (SA), multi-energy calibration (MEC), one-point gravimetric standard addition (OP GSA), one-point and multi-line calibration (OP MLC), slope ratio calibration (SRC), two-point calibration transfer (TP CT), single-sample calibration (SSC), multiple linear regression (MLR), principal component regression (PCR), partial least squares (PLS) and artificial neural networks (ANN) are discussed.
\end{abstract}

Keywords: LIBS, calibration strategies, quantitative analysis, matrix effects

\section{Introduction}

Currently, laser-induced breakdown spectroscopy (LIBS) has been reported ${ }^{1-3}$ as the most prominent spectroanalytical technique due to its attractive set of advantageous analytical characteristics. LIBS is versatile, presenting several features, such as high analytical frequency, minimal sample preparation and reagent consumption, and the ability to provide information for practically any type of sample. ${ }^{4-6}$

After advances and the establishment of the use of LIBS in several applications, it seems reasonable to repeat the words once said by Winefordner et al.:7 they stated in 2004 that LIBS would be the "next superstar" within the group of spectroanalytical techniques. This

*e-mail: erpf@ufscar.br statement can be evidenced by the number of scientific publications in the last 39 years (1981-2019) regarding LIBS with approximately 5,000 papers according to the Web of Science database, where in the last 12 years (2008-2019) account for approximately $80 \%$ of the total publications. These data exemplify the community interest in LIBS, as it is currently possible to find a wide variety of studies ${ }^{8-19}$ proposing innovations and improvements to this technique.

For qualitative analysis purposes, LIBS is well established. However, for quantitative goals, LIBS require considerable effort due to difficulties in preparing and obtaining calibration standards and the absence of commercial certified reference materials (CRM) with mass fractions on the order of $\mu \mathrm{g}$. In addition, there are problems with matrix effects, which are currently the main challenge in quantitative LIBS analysis. ${ }^{20-28}$ 
To minimize possible matrix effects normally observed in LIBS analysis, some calibration strategies have been reported in the literature ${ }^{29-35}$ over the last few years to improve its figures of merit. The main calibration strategies employed in LIBS can be divided into three groups: (i) traditional calibration, (ii) nontraditional calibration, and (iii) multivariate calibration. Our intention is to provide to the reader a clear guide about how to apply each calibration strategy correctly and in which situation to use each one. In addition, we present the advantages and limitations related to each approach.

\section{Description of the Main Matrix Effects in LIBS}

One of the inherent challenges in LIBS is quantitative analysis due to the complexity of laser-sample interaction processes, involving laser parameters, sample properties, and plasma chemistry, and due to plasma-particle interaction processes that depend on both space and time.,36 For quantitative aspects, it has always been reported ${ }^{3,36,37}$ that traditional calibration strategies applied to LIBS suffer severe matrix effects.

Besides matrix effects, there is also spectral effects that occur when a strong line interferes with the emission region of a weak line for a monitored element. This problem can easily be circumvented by selecting an alternative line of the element, carefully adjusting the peak area of the analytical signal, or switching the spectrometer arrangement for a high spectral resolution system. ${ }^{38}$ On the other hand, problems related to matrix effects are more challenging and difficult to detect and solve when compared to spectral interferences. ${ }^{39}$

Matrix effects depend on the physical characteristics and chemical compounds in the sample, and there are many possibilities for how the matrix may influence the emission phenomenon during LIBS analysis. ${ }^{38}$ Physical matrix effects are directly correlated to the different physical properties of samples, e.g., irregular surface, heterogeneity, sample moisture content, compressive pressure for sample pelleting (when applied), heat of vaporization, thermal conductivity, and absorption coefficient, which affect the transport of the ablated sample mass in the plasma. ${ }^{3,22}$

Chemical matrix effects occur due to fluctuations of the plasma parameters related to the predominant organic and inorganic composition of the sample or the content of easily ionized elements. ${ }^{40,41}$ In addition, the interaction of the laser or sample with atmospheric conditions (e.g., ambient gas or reactive gas) may affect the plasma temperature and density, resulting in changes in the emission intensity of constituent elements. ${ }^{42}$ These matrix effects may contribute to the nonstoichiometric ablation of the sample and thus reduce the ability of quantitative analysis by LIBS.

\section{Traditional Calibration Strategies Applied to LIBS}

\subsection{Matrix-matching calibration (MMC)}

Among the traditional calibration strategies applied in LIBS, MMC is the most widely used. The calibration standards in MMC are prepared in the sample matrix, usually employing certified reference materials (CRMs). However, very few CRMs that are suitable for LIBS applications are commercially available. In addition, the reference values for available CRMs are only valid for applications involving a minimum material mass (typically $100 \mathrm{mg}$ ), which is usually incompatible with the amounts required for LIBS calibration (typically a few $\mu \mathrm{g})^{2,20,21}$

MMC can also be based on a set of samples with reference values that are obtained from well-established analytical techniques or the use of solid standards with the concomitants that present interference. This strategy is very interesting and, in many cases, solves matrix effects problems because the samples themselves are used to obtain calibration curves. ${ }^{43}$ The MMC method has been effectively applied to elemental determination in different types of matrices. ${ }^{44-51}$

\subsection{Internal standardization (IS)}

The IS method consists of adding an element as the internal standard to all samples, calibration standards and analytical blank and using the analyte/internal standard signal ratio to obtain a calibration curve. The internal standard has a known concentration and, ideally, both internal standard and analyte must be affected by the same processes during instrumental measurement. ${ }^{52}$

Therefore, the IS method is often applied to minimize pulse-to-pulse variations and matrix effects. Two different types of internal standards can be used; however, in both cases, the ionization and excitation energies and emission line intensity must be similar for the internal standard and the analyte. In the first approach, the emission line of the element selected as IS must be already present in the sample spectra which its intensity remains constant for all standard samples. The second approach is applied to samples with very variable composition, in which an emission line of an added element that is not present in the unknown and standard samples can be used..$^{53-56}$ 


\subsection{Standard addition (SA)}

Standard addition is also a calibration strategy widely used in LIBS, ${ }^{20}$ minimizing matrix effects in complex samples. The SA method consists of adding known quantities of the element to be determined in the unknown sample, producing a similar behavior in the calibration series to that of the unknown sample..$^{43,52}$

For using the SA method is important to point out that the sample itself is used to prepare the calibration solutions or mixtures. Thus, the matrix effects are naturally corrected, and no prior knowledge of the sample matrix is required. On the other hand, the main limitations associated with SA are the time consuming required to construct a calibration curve for each sample and the need for a considerable amount of sample. These problems become more critical for analysis of large number of samples and if a limited sample amount is available. 12,43,52 Several studies ${ }^{57-60}$ have successfully quantified analytes using SA and LIBS.

\section{Nontraditional Calibration Strategies Applied to LIBS}

In this section, we present calibration strategies that were recently developed for LIBS. These strategies explore the physicochemical properties of laser-induced plasma species, the use of analyte emission lines with different sensitivities, and a limited number of standards (one or two standards) to obtain a linear model or calibration curve.

\subsection{Multi-energy calibration (MEC)}

MEC is one of the most recent calibration strategies reported in the literature ${ }^{61,62}$ for minimizing matrix effects in different analytical techniques of atomic spectrometry. MEC is based on different transition energies (wavelengths) for analytical signal acquisition from the analysis of two standards: pellet 1 , containing $50 \% \mathrm{~m} \mathrm{~m}^{-1}$ sample and $50 \% \mathrm{~m} \mathrm{~m}^{-1}$ standard and pellet 2, containing $50 \% \mathrm{~m} \mathrm{~m}^{-1}$ sample and $50 \% \mathrm{~m} \mathrm{~m}^{-1}$ blank. Analytical signals acquired from pellets 1 and 2 are plotted on the $x$-axis and $y$-axis (see Figure 1), respectively. Using the slope of the linear model and the analyte concentration of the standard $\left(\mathrm{C}^{\text {Standard }}\right)$ added in the pellet 1 , it is possible to obtain the analyte concentration in the sample $\left(\mathrm{C}^{\text {Sample }}\right){ }^{61}$ As shown in the Boltzmann equation (equation 1), the analyte concentration $\left(\mathrm{C}_{\mathrm{s}}\right)$ and excitedstate transition energy $\left(\mathrm{E}_{\mathrm{k}}\right)$ are related to the instrument response at a given wavelength $\left(\lambda_{i}\right) . F$ is the experimental factor, $A_{k j}$ the transition probability, $g_{k}$ the degeneration of the upper level, $U_{s}(T)$ the partition function of the species

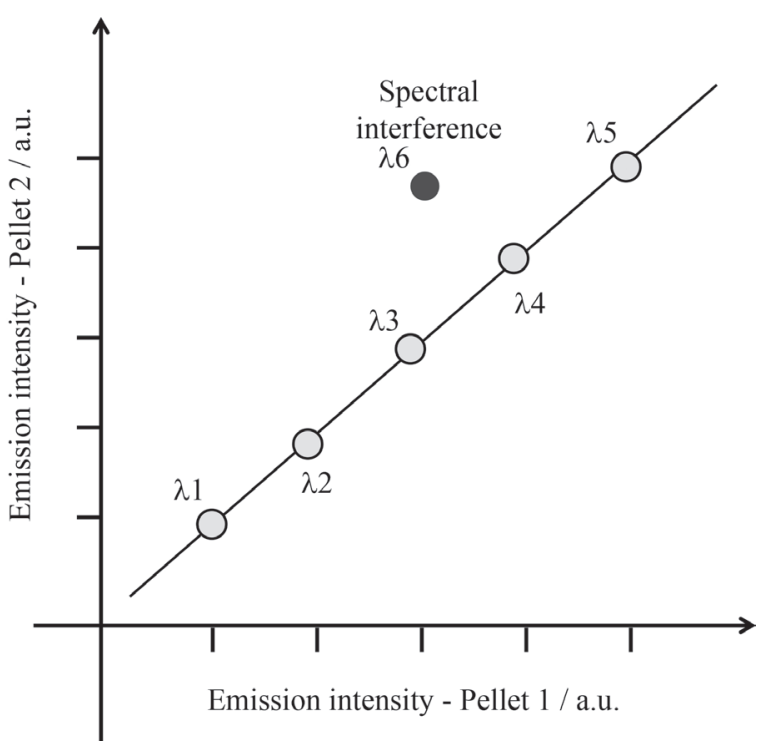

Figure 1. MEC plot and spectral interference at wavelength 6 (outlier).

present in the plasma, $\mathrm{T}$ the temperature of the plasma and $\mathrm{K}_{\mathrm{B}}$ the Boltzmann constant. If $\mathrm{C}_{\mathrm{s}}$ is fixed and $\mathrm{E}_{\mathrm{k}}$ is changed by using different wavelengths during the analytical signal acquisition, the instrument response is a dependent variable of both parameters.

Considering $\mathrm{C}^{\text {Standard }}, \mathrm{C}^{\text {Sample }}$ and a simple mathematical treatment used for elemental determination, it is possible to obtain equations 2 and $3:{ }^{61}$

$\mathrm{I}_{\lambda_{\mathrm{i}}}=\mathrm{FC}_{\mathrm{s}} \frac{\mathrm{A}_{\mathrm{kj}} \mathrm{g}_{\mathrm{k}}}{\mathrm{U}_{\mathrm{s}}(\mathrm{T})} \mathrm{e}^{-\mathrm{E}_{\mathrm{k}} / \mathrm{K}_{\mathrm{B}} \mathrm{T}}$

$\mathrm{I}\left(\lambda_{\mathrm{i}}\right)^{\text {Sample+Standard }}=\mathrm{K}_{\mathrm{p}}\left(\mathrm{C}^{\text {Sample }}+\mathrm{C}^{\text {Standard }}\right)$

$\mathrm{I}\left(\lambda_{\mathrm{i}}\right)^{\text {Sample }}=\mathrm{K}_{\mathrm{p}} \mathrm{C}^{\text {Sample }}$

where the terms $\mathrm{C}^{\text {Standard }}$ and $\mathrm{C}^{\text {Sample }}$ were defined previously, $\mathrm{I}\left(\lambda_{\mathrm{i}}\right)^{\text {Sample+Standard }}$ and $\mathrm{I}\left(\boldsymbol{\lambda}_{\mathrm{i}}\right)^{\text {Sample }}$ are the instrument response at a given wavelength $\left(\lambda_{i}\right)$ for both pellets, and $K_{p}$ is a proportionality constant. After reorganization of equations 2 and 3 , it is possible to calculate $\mathrm{C}^{\text {Sample }}$ from equation 4 :

$\mathrm{C}^{\text {Sample }}=\frac{\text { Slope } \times \mathrm{C}^{\text {Standard }}}{(1-\text { Slope })}$

The main advantages of MEC are related to the matrixmatching capability due to the presence of the sample in the standards (pellets 1 and 2) and the possibility of identifying spectral interferences, as shown in Figure 1. Emission line number $6\left(\lambda_{6}\right)$ is an outlier, where its signal is shifted from the proposed linear model plot, indicating that $\lambda_{6}$ is an emission line with spectral interference and must be removed and the model calculated again. 
In this sense, Babos et al..$^{29}$ applied MEC as a calibration strategy, for the first time, for the analysis of cattle mineral supplements by LIBS. The authors used different salts to prepare solid stock standards containing the analytes. Highpurity sodium carbonate $\left(\mathrm{Na}_{2} \mathrm{CO}_{3}\right)$ was used as a blank (and as a diluent) to simulate the matrix of the analyzed samples due to the presence of carbonates. To build the linear models, several atomic (I) and ionic (II) emission lines were selected from the most sensitive lines for each analyte.

In addition, the authors also evaluated the influence of different standard mass (that is, different $C^{\text {Standard }}$ values) added to pellet 1 on the accuracy of the results. The precision, described as the relative standard deviation (RSD), ranged from 2 to $32 \%$, and the trueness varied from 85 to $102 \%$ using MEC-LIBS. According to the $t$-test, at the $95 \%$ of confidence level, no significant difference was observed between the reference results obtained by inductively coupled plasma optical emission spectrometry (ICP OES) or reference materials and MEC-LIBS.

Some important aspects should be highlighted: $(i)$ the selection of a blank material is a challenge because it must be a high-purity reagent to avoid contamination during the analysis, contributing to better method precision, and, at the same time, must have a similar composition to the matrix of the samples to be analyzed; (ii) the homogenization of the standard and blank material with the samples is a crucial aspect because a failure to do so can compromise the precision and the accuracy of the proposed method.

Some studies in the scientific literature ${ }^{30,33,63-66}$ have reported elemental determination in different samples using the MEC-LIBS method with good analytical performance parameters (Table 1).

\subsection{One-point gravimetric standard addition (OP GSA)}

SA is a calibration strategy that consists of increasing the analyte concentration in the samples, which are then plotted on the $x$-axis, and the analytical signals (S) are plotted on the $y$-axis. Thus, in an unknown sample, the analyte concentration can be calculated using equation 5 proposed by Bader: ${ }^{67}$

$\mathrm{C}_{\mathrm{x}}=\frac{\text { intercept } \mathrm{V}_{\mathrm{s}} \mathrm{C}_{\mathrm{s}}}{\text { slope } \mathrm{V}_{\mathrm{x}}}$

where the intercept and the slope were obtained from the calibration curve, $\mathrm{V}_{\mathrm{s}}$ is the fixed unit volume of the standard, $\mathrm{V}_{\mathrm{x}}$ is the fixed unit volume of the unknown sample, $\mathrm{C}_{\mathrm{s}}$ is the stock standard concentration and $C_{x}$ is the unknown sample concentration.

For direct analysis of solids, a new gravimetric approach (G) was introduced to SA that considers masses instead of volumes. In 2008, Kelly et al. ${ }^{68}$ reformulated equation 5 , considering the mass of the standard $\left(\mathrm{m}_{\mathrm{s}}\right)$, the unknown sample mass $\left(\mathrm{m}_{\mathrm{x}}\right)$ and the mass of the diluent $\left(\mathrm{m}_{\mathrm{D}}\right)$.

In gravimetric SA, the $x$-axis is represented by equation 6 , the $y$-axis is represented by equation 7 , and $\mathrm{C}_{\mathrm{x}}$ is calculated using equation $8:^{68}$

$x$ axis $=\frac{\mathrm{m}_{\mathrm{s}} \mathrm{C}_{\mathrm{s}}+\mathrm{m}_{\mathrm{D}} \mathrm{C}_{\mathrm{D}}}{\mathrm{m}_{\mathrm{x}}}$

Table 1. MEC-LIBS methods applications

\begin{tabular}{|c|c|c|c|c|c|c|}
\hline Sample & Analyte & $\begin{array}{c}\text { Sample/standard } \\
\text { or blank ratio / } \\
\left(\% \mathrm{~m} \mathrm{~m}^{-1}\right) \\
\end{array}$ & $\mathrm{RSD} / \%$ & Trueness / \% & Highlight & Reference \\
\hline $\begin{array}{l}\text { Mineral supplements } \\
\text { for cattle }\end{array}$ & $\mathrm{Ca}$ and $\mathrm{P}$ & $80: 20$ & 4 to 26 & 80 to 109 & $\begin{array}{l}\mathrm{Na}_{2} \mathrm{CO}_{3} \text { was used as the blank (and diluent); } \\
\text { identified one spectral interference for } \mathrm{P}\end{array}$ & 30 \\
\hline Hard disk magnets & $\begin{array}{l}\mathrm{Fe}, \mathrm{B}, \mathrm{Dy}, \mathrm{Gd}, \mathrm{Nd}, \\
\text { Pr, Sm and } \mathrm{Tb}\end{array}$ & $42: 58$ & 3 to 44 & 80 to 120 & $\begin{array}{l}\mathrm{Na}_{2} \mathrm{CO}_{3} \text { was used as the blank, cellulose was used as } \\
\text { a binder, and a sample was selected as the standard }\end{array}$ & 33 \\
\hline Dietary supplements & $\mathrm{Ca}, \mathrm{K}$ and $\mathrm{Mg}$ & $50: 50$ & $<56$ & 60 to 120 & $\begin{array}{c}\text { microcrystalline cellulose was used as the blank } \\
\text { and diluent; evaluation of the influence of different } \\
\text { proportions of the analyte in the stock solid mixture } \\
\text { on analytical signals }\end{array}$ & 63 \\
\hline Nickeliferous ores & $\mathrm{Ni}$ and $\mathrm{Cr}$ & $50: 50$ & 1 to 9 & 89 to 114 & $\mathrm{Na}_{2} \mathrm{CO}_{3}$ as the blank and diluent & 64 \\
\hline $\begin{array}{l}\text { Liquid crystal } \\
\text { display }\end{array}$ & In & $40: 60$ & 12 to 20 & 80 to 120 & $\begin{array}{l}\mathrm{SiO}_{2} \text { was used as the blank and cellulose as a binder; } \\
\text { identified one spectral interference for In }\end{array}$ & 65 \\
\hline $\begin{array}{l}\text { High-silicon-content } \\
\text { samples }\end{array}$ & $\mathrm{Al}, \mathrm{Fe}$ and $\mathrm{Ti}$ & $50: 50$ & 4 to 7 & 88 to 115 & $\begin{array}{l}\text { fused glass disks were prepared from CRM (brick } \\
\text { clay and sediment), } \mathrm{SiO}_{2} \text { and a lithium borate flux } \\
\text { mixture; after the fusion procedure, fused samples } \\
\text { were analyzed considering five emission lines for } \mathrm{Al} \text {, } \\
\text { seven for } \mathrm{Fe} \text { and five for } \mathrm{Ti} \text {; } \mathrm{B} \text { and } \mathrm{Li} \text { were evaluated } \\
\text { as internal standards }\end{array}$ & 66 \\
\hline
\end{tabular}

RSD: relative standard deviation; CRM: certified reference material. 
$y$ axis $=\frac{m_{x}+m_{s}+m_{D}}{m_{x}} S$

$\mathrm{C}_{\mathrm{x}}=\frac{\mid \text { intercept } \mid}{\text { slope }}$

where $C_{D}$ is the analyte concentration in the diluent, and the term $m_{D} C_{D}$ can be neglected in equation 6 because the diluent is usually of high purity, and $\mathrm{S}$ is the analyte signal. In addition to its advantages, SA usually requires five points, which causes long preparation of solid calibration standards for each sample.

Moreover, for the first time, Babos et al. ${ }^{30}$ proposed OP GSA for direct solid analysis by LIBS. This strategy uses two calibration standards (sample + blank and sample + standard), similar to the standards prepared when using MEC, and only one wavelength is monitored. Figure 2 shows an example of the calibration curve employing OP GSA by LIBS, in which the unknown concentration of analyte in the sample is calculated by extrapolation of the calibration curve, according to equation 8 .

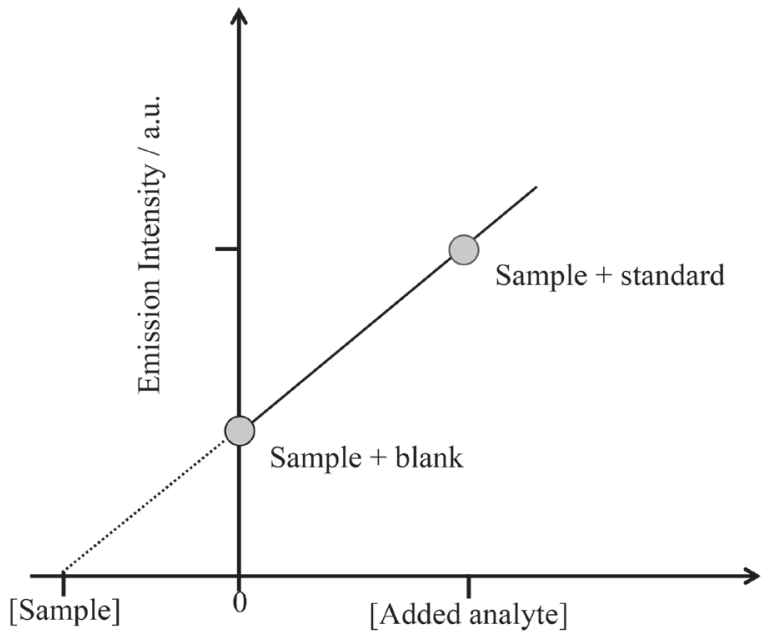

Figure 2. OP GSA calibration curve.

In the literature, only two studies are available employing OP GSA, including one for determination of $\mathrm{Ca}$ and $\mathrm{P}$ in solid mineral supplements ${ }^{30}$ and one for determination of B, Fe, Dy, Gd, Nd, Pr, Sm and Tb in hard disk magnets. ${ }^{33}$ In general, the authors obtained sufficient RSD values (ranging from 1 to $39 \%$ in mineral supplement and 2 to $44 \%$ in hard disk magnet determinations, in addition to adequate trueness).

The OP GSA method has an advantage over conventional SA because it requires a small amount of sample to prepare the standards which only one SA point is used, and, consequently, there is a higher analytical throughput.

\subsection{One-point and multiline calibration (OP MLC)}

OP MLC is a new calibration strategy based on a single matrix-matched standard sample and multiple lines of determined elements. The main idea is that from the local thermodynamic equilibrium (LTE) in the temporal window of signal acquisition, the measured integral line intensity can be expressed according to the Boltzmann equation, as shown in equation $1 .^{31}$

Therefore, measuring the intensity of spectral line $I_{\lambda 1}$ is proportional to $I_{\lambda 2}$ from the same species under the same plasma conditions. Moreover, if two emission lines $\lambda_{1}$ and $\lambda_{2}$ are emitted from the same element but in different samples, their intensity ratio can be expressed by equation 9 :

$\frac{\mathrm{C}_{\mathrm{s}}^{\mathrm{a}}}{\mathrm{C}_{\mathrm{s}}^{\mathrm{b}}}=\frac{\mathrm{I}_{\lambda_{\mathrm{I}}}^{\mathrm{a}}}{\mathrm{I}_{\lambda_{\mathrm{I}}}^{\mathrm{b}}}$

where $\mathrm{a}$ and $\mathrm{b}$ indicate two different samples and $\mathrm{C}_{\mathrm{s}}^{\mathrm{a}}$ and $\mathrm{C}_{\mathrm{s}}^{\mathrm{b}}$ are the concentrations of species in samples $\mathrm{a}$ and $\mathrm{b}$. Therefore, the unknown concentration of the determined species can be obtained by employing only one sample as a standard in which the concentration of the analytes must be certified or known.

According to the authors, ${ }^{31}$ the use of a single line cannot be guaranteed due to background of the spectrum and intensity errors that can affect the unknown concentration. An alternative for this problem is to use the intensities of multiple lines of a standard or certified material and unknown samples to build a linear model, as shown in Figure 3. In addition, equation 9 was reformulated by replacing the intensity ratio $\mathrm{I}_{\lambda_{\mathrm{I}}}^{\mathrm{a}} / \mathrm{I}_{\lambda_{\mathrm{I}}}^{\mathrm{b}}$ with the slope of the linear model. Therefore, equation

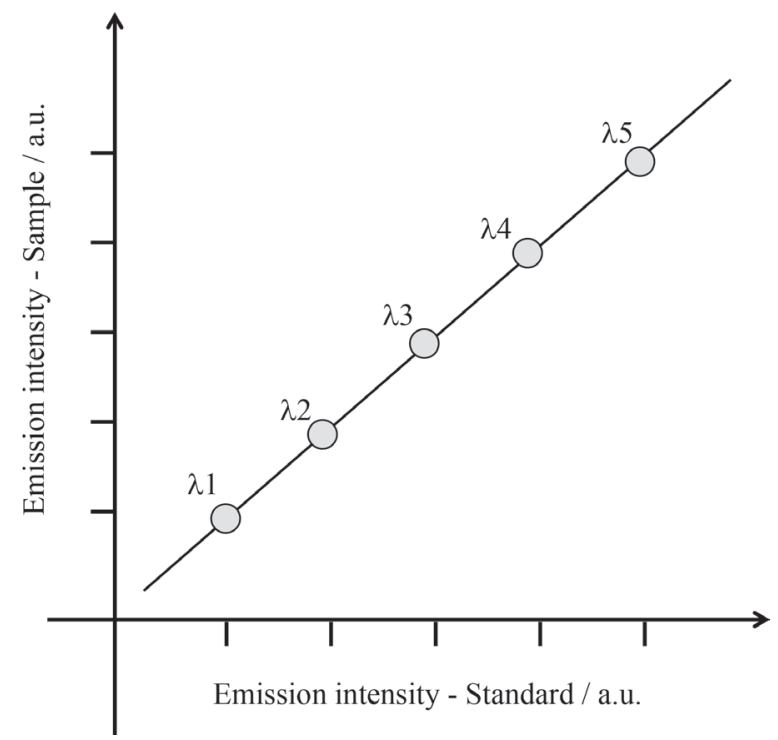

Figure 3. OP MLC linear model for five spectral lines of an analyte. 
10 can be used to calculate the concentration of the analytes in the unknown samples.

$$
\mathrm{C}_{\text {analyte }}=\text { slope } \times \mathrm{C}_{\text {standard }}
$$

Using OP MLC for quantitative determination by LIBS simplifies the analysis because it does not require a large number of standards and complicated calculations. In the literature, only one study ${ }^{31}$ has reported the use of OP MLC for $\mathrm{Mn}, \mathrm{Cr}, \mathrm{Ni}$, Ti and $\mathrm{Fe}$ determination in standard low-alloy steel samples with average relative errors for determination in the range of $9-36 \%$.

\subsection{Slope ratio calibration (SRC) and two-point calibration transfer (TP CT)}

The SRC method is a calibration strategy recently proposed by Nunes et al..$^{32}$ This strategy is related to the increase of the ablated sample mass with the number of accumulated laser pulses on a single calibration standard. The emission intensity (I) is directly proportional to the analyte amount in the ablated sample mass (m), which, in turn, is proportional to the number of laser pulses (Np). Process related to sample ablation $\left(\mathrm{k}_{1}\right)$, and analyte atomization and excitation efficiency $\left(\mathrm{k}_{2}\right)$ are shown by proportionality $(\mathrm{K})$ between I and Np, according to equation 11.

$$
\left\{\begin{array}{c}
\mathrm{I}=\mathrm{k}_{1} \mathrm{~m} \\
\mathrm{~m}=\mathrm{k}_{2} \mathrm{~N}_{\mathrm{p}} \\
\mathrm{I}=\mathrm{KN}_{\mathrm{p}} \\
\mathrm{K}=\mathrm{k}_{1} \mathrm{k}_{2} \mathrm{k}_{\mathrm{n}}
\end{array}\right\}
$$

Two linear models are generated in SRC, one for a sample with an unknown analyte concentration and the other for a calibration standard, which can be a CRM or reference sample. These two models are obtained by plotting the analyte emission intensity as a function of the number of accumulated laser pulses in the sample and in the standard, as shown in Figure 4a. The analyte mass fractions in the sample with unknown concentrations are determined from the ratio of the corresponding slopes of these linear models.

Using the reference concentration $\left(\mathrm{C}_{\text {standard }}\right)$ of the analyte in the calibration standard and the slope ratio obtained in the linear models for the sample ( slope $_{\text {sample }}$ ) and calibration standard (slope standard $_{\text {) }}$, the analyte concentration $\left(\mathrm{C}_{\text {analyte }}\right)$ can be obtained using equation 12 .

$\mathrm{C}_{\text {analyte }}=\frac{\text { slope }_{\text {sample }}}{\text { slope }_{\text {standard }}} \times \mathrm{C}_{\text {standard }}$

SRC was employed for the determination of $\mathrm{B}, \mathrm{Ca}, \mathrm{Cu}$, $\mathrm{Fe}, \mathrm{Mg}, \mathrm{Mn}, \mathrm{P}$ and $\mathrm{Zn}$ in plant leaves using between 5 and 30 laser pulses per site for calibration. Analysis of CRMs and comparison with the results obtained by ICP OES were used to verify the accuracy of the SRC calibration strategy, with agreement at the $95 \%$ confidence level.

The TP CT method is another interesting calibration strategy and it was recently proposed by Castro et al..$^{33} \mathrm{It}$ is derived from the SRC approach with the difference of using only two points of accumulated laser pulses. Therefore, the linear model for the sample and standard is obtained

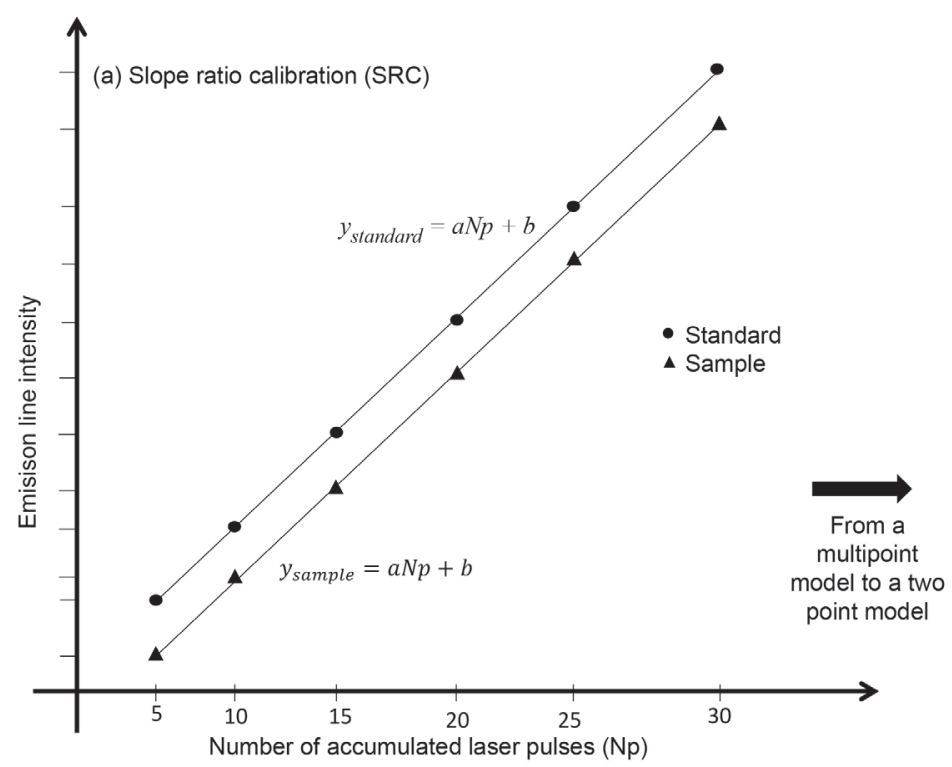

Figure 4. Linear models obtained for the sample and standard using (a) SRC and (b) TP CT for LIBS. 
with two analytical signals monitoring only one analyte emission line, as can be seen in Figure 4b. The interest analyte concentration is also calculated as the SRC method (equation 12).

As in LIBS, hundreds of spectra are obtained for representative analysis, so it is easy to obtain two sets of spectra for the linear model plot. In addition, the sum of the intensity of the spectra obtained for each set should be used as data pretreatment. ${ }^{33}$ According to the pioneering study, ${ }^{33}$ the second set of spectra must be at least twice as large as the first set to obtain good linearity of the models. The linearity is obtained calculating the $F$-values ( $F_{\text {experimental }}$ and $F_{\text {tabulated }}$ ) from the mean of square of regression and residue (MSR and $\mathrm{MSr}$, respectively). If the ratio of $F_{\text {experimental }} / F_{\text {tabulated }}$ is $\geq 10$, the model is considered statistically valid with good linearity. ${ }^{30,69-71}$

A limitation of both methods (SRC and TP CT) is the difficulty in choosing an appropriate standard for obtaining a linear model for subsequent calibration transfer. The laser-to-sample/standard interaction depends on the physicochemical characteristics of the sample, the laser properties and the optical design. ${ }^{32}$ Therefore, it is necessary that the unknown sample and the standard have similar characteristics and concentrations of the analyte for a perfect matrix-matching. In addition, the analysis in LIBS should be performed using the same parameters for both samples (unknown and standard). ${ }^{33}$

TP CT was successfully employed for the direct analysis and determination of base and rare earth elements in eight obsolete hard disk magnets. The RSD values varied from 2 to $28 \% .{ }^{33}$ TP CT has also been successfully used by Gamela et al..$^{70}$ for the direct determination of $\mathrm{Ca}, \mathrm{K}$ and $\mathrm{Mg}$ in cocoa beans. The last three calibration possibilities presented (OP GSA, SRC and TP CT) require the selection of an emission line free of spectral interference. In this case, a good strategy is to first use MEC, identify the emission lines that are free of spectral interference and apply these lines in the calibration strategies that employ signal from an individual emission line.

\subsection{Single-sample calibration (SSC)}

The SSC method was recently proposed by Yuan et al..$^{34}$ This strategy is based on the Lomakin-Scherb formula, where the emission intensity of a spectral line of element $j$ is equal to the multiplication of an experimental factor by the concentration of element $\mathrm{j}$. Thus, to estimate the concentration of the analyte only one sample (CRM or sample with a reference concentration) is used as a calibration standard and subsequent correlation is calculated between the different emission lines of the analyte and other elements present in the standard and sample (unknown) and the concentration of all these elements present in the calibration standard.

The SSC method requires only a correlation between emission line intensity and concentration, eliminating the necessity to construct a calibration curve or linear models. The highlight of this strategy is that the analyte emission line and other emission lines of the elements present in the plasma formed after sample ablation are employed in this correlation to estimate the analyte concentration, which enables good accuracy in the determinations. ${ }^{34}$

Thus, the analyte concentration $\left(\mathrm{C}_{\text {analyte }}\right)$ is calculated using equation 13 :

$$
\mathrm{C}_{\text {analyte }}=\frac{\frac{\mathrm{C}_{\text {standard analyte }} \times \mathrm{I}_{\text {analyte sample }}}{\mathrm{I}_{\text {analyte standard }}}}{\sum_{\mathrm{i}=1}^{\mathrm{N}} \frac{\mathrm{C}_{\text {standard element }}^{\mathrm{N}} \times \mathrm{I}_{\text {element sample }}^{\mathrm{N}}}{\mathrm{I}_{\text {element standard }}^{\mathrm{N}}}}
$$

where $\mathrm{C}_{\text {standard analyte }}$ and $\mathrm{I}_{\text {analyte standard }}$ are the concentration and intensity of the emission line of the analyte in the sample used as a calibration standard, respectively; $\mathrm{I}_{\text {analyte sample }}$ is the emission intensity of the analyte in the unknown sample, $\mathrm{I}_{\text {element sample }}^{\mathrm{N}}$ is the emission intensity of the element $\mathrm{N}$ in the sample of unknown concentration, and $\mathrm{C}_{\text {standard element }}^{\mathrm{N}}$ and $\mathrm{I}_{\text {element standard }}^{\mathrm{N}}$ are the concentration and the emission intensity of the element $\mathrm{N}$, respectively, in the sample used as a calibration standard. ${ }^{34}$

In SSC there is a direct correlation among the concentration and emission line intensities of the elements present in the plasma. It is important to mention for the concentration estimation that both standard and sample need to have similar physicochemical properties to minimize the matrix effects and, in addition, the selection of emission lines free of spectral interference.

In the study of Yuan et al., ${ }^{34} \mathrm{SSC}$ was employed to determine $\mathrm{Fe}, \mathrm{Cu}, \mathrm{Zn}, \mathrm{Ni}, \mathrm{Cr}, \mathrm{Nb}$, and Mo in steel, brass, and nickel-based microalloy samples. The analytical figures of merit obtained using SSC showed better results than those of matrix-matching calibration (multipoint calibration). ${ }^{34}$

\section{Multivariate Calibration}

Unlike univariate calibration, multivariate analysis is the study of several variables measured in a certain number of samples, of which the aim is to determine all types of variation in the data. This calibration refers as first-order calibration, where a vector is determined for each sample. Therefore, chemometric tools attempt to find the relationship between samples (scores) and variables (loadings). ${ }^{72-74}$ 
Some advantages of multivariate calibration are noted as follows: (i) noise reduction is accomplished using multiple responses, improving the precision and obtaining robustness towards random artifacts; (ii) interferents can be handled when these interfering species are included in the calibration model and both signals (interferent and analyte) are not completely identical. On the other hand, if these species are not included in the calibration model, the presence of interference can be detected but not corrected; (iii) several parameters are obtained with the models, which can be used to investigate, understand and improve the model. With the scores, it is possible to observe the presence of outliers, for instance, where extreme scores can indicate an extreme sample (possibly an outlier).

To predict samples from validation with the calibration model, one important aspect is that the new sample should contain the same characteristics as those of the samples for which the calibration model was built; otherwise, the deviation can be observed, containing unmodeled variation, where the new samples cannot be accurately predicted with the model. ${ }^{75-77}$

There are many tools for multivariate calibration, such as multiple linear regression (MLR), ${ }^{78,79}$ principal component regression (PCR), ${ }^{80,81}$ partial least squares (PLS), ${ }^{82,83}$ and artificial neural networks (ANN) ${ }^{84,85}$ According to Web of Science, since 2000, the number of publications with LIBS and multivariate calibration has presented a systematic increase, and among the methods mentioned, PLS proved to be included in the most published papers, followed by those reporting on ANN, PCR and MLR, as showed in Figure 5. In addition, Table 2 presents some applications of multivariate calibration in LIBS. ${ }^{59,80,86-93}$

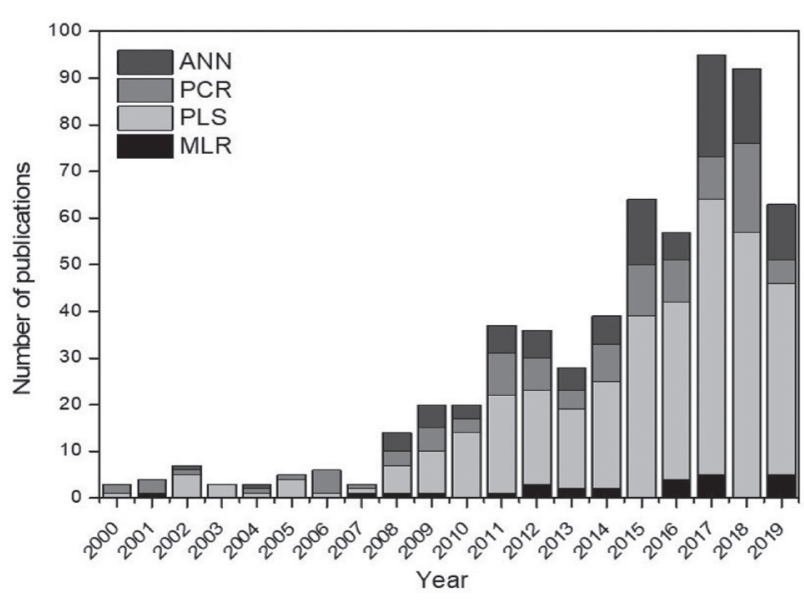

Figure 5. Publications since 2000 about multivariate calibration and LIBS.

\section{Conclusions and Perspectives}

After evaluation of this review, the reader is probably asking: what is the best calibration strategy for LIBS? This is a very difficult question and depends on several factors, such as sample type, availability of standards (or reference values), correction or removal of the background signal, besides spectral normalization procedures. Currently, the calibration possibilities for quantitative analysis by LIBS are diverse. However, the optimal calibration will be one that allows determinations with satisfactory accuracy and precision, i.e., one that minimizes matrix effects in the analyte determination. The choice of the calibration strategy employed in the analytical method to be developed will depend on the intrinsic properties of the sample analyzed and the knowledge of the advantages and limitations inherent to each strategy. Table 3 briefly outlines the advantages and limitations of each calibration strategy presented in this review.

Table 2. Applications of multivariate calibration in LIBS

\begin{tabular}{lccc}
\hline Goal & Sample & Calibration method & Reference \\
\hline Ti quantification & sunscreen & MLR, PCR and PLS & 80 \\
$\mathrm{~Pb}$ quantification & tea leaves & external standard, IS and MLR & 59 \\
Total carbon concentration & soil & MLR & PCR \\
Mn quantification & glass matrices & PCR and PLS & 86 \\
$\mathrm{Cu}$ and $\mathrm{Zn}$ quantification & brass alloys & PLS & 88 \\
$\mathrm{PC}$ and ABS concentration & plastics (PC/ABS) from WEEE & PLS & 89 \\
Clay, silt and sand percent & soil & ANN & 90 \\
Cu quantification & soil & ANN & 91 \\
Quantification of trace levels of uranium & forensic nuclear materials & ANN & 92 \\
$\mathrm{Cr}$, Mg, Mn and Cu determination & Al alloys & 93 \\
\hline
\end{tabular}

MLR: multiple linear regression; PCR: principal component regression; PLS: partial least squares; IS: internal standardization; PC: polycarbonate; ABS: acrylonitrile butadiene styrene; WEEE: waste of electrical and electronic equipment; ANN: artificial neural networks. 
Table 3. Advantages and limitations of the calibration strategies applied in LIBS

\begin{tabular}{|c|c|c|}
\hline Calibration strategy & Advantages & Limitations \\
\hline Matrix-matching calibration (MMC) & $\begin{array}{l}\text { minimizes matrix effects because the chemical } \\
\text { properties of the standards and samples are } \\
\text { similar }\end{array}$ & $\begin{array}{c}\text { few certified reference materials are } \\
\text { commercially available, as well as samples with } \\
\text { reference values }\end{array}$ \\
\hline Internal standardization (IS) & $\begin{array}{l}\text { minimizes matrix effects and fluctuations in } \\
\text { instrumental measurements }\end{array}$ & $\begin{array}{l}\text { difficulty choosing an appropriate internal } \\
\text { standard }\end{array}$ \\
\hline Standard addition (SA) & minimizes matrix effects in complex samples & requires considerable amount of sample \\
\hline Multi-energy calibration (MEC) & $\begin{array}{l}\text { minimizes matrix effects and identifies spectral } \\
\text { interference; requires only two calibration } \\
\text { standards for each sample }\end{array}$ & $\begin{array}{l}\text { difficulty choosing an appropriate blank } \\
\text { (diluent) }\end{array}$ \\
\hline $\begin{array}{l}\text { One-point gravimetric standard addition } \\
\text { (OP GSA) }\end{array}$ & $\begin{array}{c}\text { minimizes the effects of matrix in complex } \\
\text { samples and requires only a small amount of } \\
\text { sample }\end{array}$ & $\begin{array}{l}\text { requires effective sample homogenization with } \\
\text { blank or standard }\end{array}$ \\
\hline $\begin{array}{l}\text { One-point and multi-line calibration } \\
\text { (OP MLC) }\end{array}$ & $\begin{array}{l}\text { requires only one calibration standard and } \\
\text { minimizes matrix effects }\end{array}$ & $\begin{array}{l}\text { difficulty choosing an appropriate calibration } \\
\text { standard }\end{array}$ \\
\hline Slope ratio calibration (SRC) & $\begin{array}{l}\text { minimizes the effects of matrix and only a } \\
\text { reference sample or CRM is used as a standard }\end{array}$ & $\begin{array}{l}\text { the concentration of analytes in the samples } \\
\text { should be similar to the standard concentration, } \\
\text { and the linear model is multipoint }\end{array}$ \\
\hline Two-point calibration transfer (TP CT) & $\begin{array}{l}\text { minimizes the effects of matrix, only a sample } \\
\text { or CRM is used as a standard; simplicity in data } \\
\text { processing; linear model is with only two points }\end{array}$ & $\begin{array}{l}\text { the concentration of analytes in the samples } \\
\text { should be similar to the standard concentration }\end{array}$ \\
\hline Single-sample calibration (SSC) & $\begin{array}{l}\text { requires only one calibration standard, and does } \\
\text { not require a calibration curve or linear model } \\
\text { (only one correlation) }\end{array}$ & $\begin{array}{c}\text { difficulty choosing an appropriate calibration } \\
\text { standard }\end{array}$ \\
\hline Multiple linear regression (MLR) & calibration in the presence of interferents & $\begin{array}{l}\text { the sample number must be greater than the } \\
\text { number of variables (collinearity) }\end{array}$ \\
\hline Principal component regression (PCR) & calibration in the presence of interferents & requires large number of samples for calibration \\
\hline Partial least squares (PLS) & calibration in the presence of interferents & requires large number of samples for calibration \\
\hline Artificial neural networks (ANN) & $\begin{array}{l}\text { calibration in the presence of interferents and the } \\
\text { capacity to model nonlinear signals }\end{array}$ & $\begin{array}{c}\text { requires large sample sizes for calibration and } \\
\text { analyst expertise }\end{array}$ \\
\hline
\end{tabular}

CRM: certified reference material.

The authors of this review expect that the information presented here will help readers and LIBS users successfully perform quantitative analysis. Several different calibration methods (univariate and multivariate) were presented, emphasizing their advantages and limitations. Calibrationfree $(\mathrm{CF})$ analysis was not mentioned because it is beyond the scope of our intentions. In our opinion, this review can aid users in the selection of a proper calibration alternative, fostering the application of LIBS for several types of samples. The challenges are many, but from the literature, it is possible to conclude that LIBS is already a superstar technique.

\section{Acknowledgments}

The authors are grateful to the Conselho Nacional de Desenvolvimento Científico e Tecnológico (CNPq, grants 141311/2017-7, and 158587/2017-0, CNPq/TWAS) for fellowships and financial support. This study was financed in part by the Coordenação de Aperfeiçoamento de Pessoal de Nível Superior, Brazil (CAPES), finance code 001 and the São Paulo Research Foundation (FAPESP, grants 2019/24223-5, 2016/01513-0, 2016/17304-0, 2016/17221-8, 2018/24569-6, and 2018/17753-5).

\section{Author Contributions}

Vinicius C. Costa, Diego V. Babos and Jeyne P. Castro were responsible for formal analysis, conceptualization, visualization, writing original draft, review and editing; Daniel F. Andrade, Raimundo R. Gamela and Raquel C. Machado for formal analysis, visualization, writing original draft, review and editing; Marco A. Sperança, Alisson S. Araújo and José A. Garcia for formal analysis, conceptualization and visualization; Edenir R. PereiraFilho for formal analysis, funding acquisition, project administration, resources, supervision, visualization, writing review and editing. 


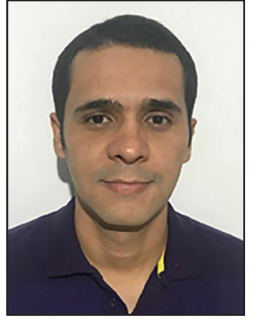

Vinicius C. Costa is graduated in Chemistry in 2013 at Universidade Estadual de Santa Cruz (UESC), Brazil, where he got his Master's degree, in 2015. In 2019, received a PhD degree in Science by Universidade Federal de São Carlos (UFSCar). Nowadays, is a Postdoctoral researcher in Brazil at Universidade Federal do Espírito Santo (UFES). He has experience in analytical chemistry with emphasis on direct analysis of solids by laser-induced breakdown spectroscopy (LIBS) and wavelength dispersive $X$-ray fluorescence (WD-XRF). In addition, he works with chemometrics tools as: design of experiments, supervised and unsupervised methods and multivariate calibration. He is the author/co-author of 35 papers published in international peer-reviewed journals and has an $H$ factor of 9.

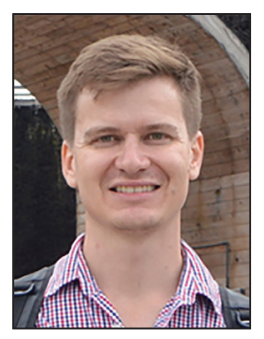

Diego V. Babos is graduated in Chemistry at Universidade Federal de Viçosa (UFV, Rio Paranaíba), Master's degree at Chemistry Institute UNESP, Araraquara, and PhD degree in Sciences (Analytical Chemistry) at Universidade Federal de São Carlos, Brazil, with sandwich period at Universidad de Zaragoza, Spain, 2020. His research interests are centered in direct solid analysis by atomic spectroscopic technique (HR-CS GFAAS, LIBS, XRF and $X A N E S)$, chemometrics tools and sample preparation. He is the author/co-author of 25 papers published in international peer-reviewed journals.

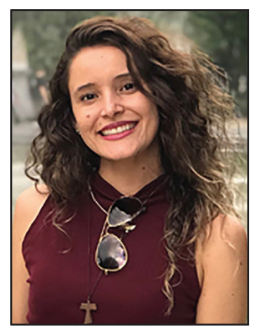

Jeyne P. Castro is graduated in Chemistry at Universidade Federal de Viçosa, Campus Rio Paranaíba (2014). Master in Analytical Chemistry at Universidade Federal de São Carlos (UFSCar, 2017). Presently, she is a PhD student at UFSCar under supervision of Prof Dr Edenir R. Pereira-Filho, where her work was developed partly at the University of Copenhagen (Denmark) under supervision of Prof Dr Rasmus Bro. Her experience is in the area of analytical chemistry focusing on spectroanalytical techniques (LIBS, ICP OES, XRF), sample preparation, direct analysis of solids and data processing using chemometric tools. She is the author/co-author of 13 papers published in international peer-reviewed journals.

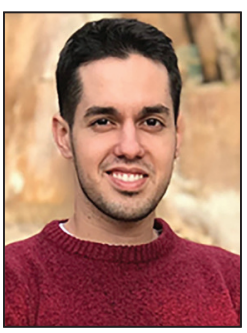

Daniel F. Andrade is graduated in Chemistry in 2015 at Universidade Federal de Viçosa, Campus Rio Paranaíba (UFV-CRP). He got his Master's degree in Chemistry (Analytical Chemistry) at Universidade Federal de São Carlos (UFSCar), in 2017. Currently, he is a PhD student at UFSCar in the development of analytical methods for direct characterization of electronic waste under the supervision of Prof Edenir R. Pereira-Filho. His work has been developed partly at Hampshire College, USA, under the supervision of Prof Dulasiri Amarasiriwardena. His research interests are centered on Analytical Chemistry, acting on the following topics: sample preparation, chemometric tools, ICP OES, ICP-MS, XRF, and laser-based techniques such as LIBS and LA-ICP-MS. He is the author/co-author of 20 papers published in international and national peer-reviewed journals and has an $H$ factor of 9.

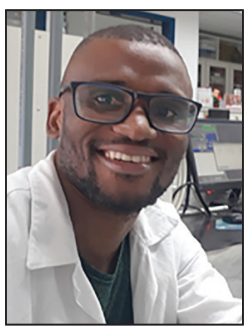

Raimundo R. Gamela is graduated in Chemistry in 2014 at Universidade Catolica de Moçambique (UCM), Mozambique. In 2017, he received Master's degree in Food Science and Technology at the Universidade Federal do Rio Grande do Sul (UFRGS), Brazil, under supervision of Prof Dr Maria Goreti Rodrigues Vale. In 2020, he obtained his PhD degree in Science (Analytical Chemistry) at Universidade Federal de São Carlos, Brazil, under the supervision of Prof Dr Edenir R. Pereira-Filho. He has experience in the following fields: direct solid analysis and sample preparation for the determination of chemical composition in food samples employing different instrumental techniques, such as laser-induced breakdown spectroscopy (LIBS), X-ray fluorescence spectroscopy (XRF), atomic absorption spectrometry (AAS) and inductively coupled plasma optical emission spectrometry (ICP OES). Moreover, he has experience in design of experiment and multivariate calibration employing different chemometric tools. Nowadays he is working at SwissLab at Maputo (Mozambique).

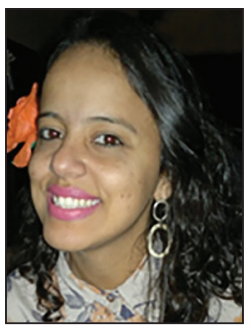

Raquel C. Machado obtained her degree in Chemistry at Federal University of Bahia (UFBA) in 2012. In 2014, she obtained Master degree in Chemistry (Analytical Chemistry) at Federal University of São Carlos (UFSCar), in the Group for Applied 
Instrumental Analysis (GAIA) under supervision of Dr Ana Rita de Araujo Nogueira (Embrapa Pecuária Sudeste), where she obtained PhD degree (2018). According to specific collaboration agreement, she also obtained PhD degree at Universidad of Zaragoza, Spain (2018). Currently, she is a Postdoctoral Fellow at GAIA-UFSCar under the supervision of Prof Dr Edenir R. Pereira-Filho. She has experience in Analytical Chemistry, with emphasis on sample preparation, solid sampling, and direct analysis, atomic absorption spectrometry (FAAS, HG AAS, HR CS GFAAS) and plasma source techniques (MIP OES, ICP OES, ICP-MS and LIBS), topics to which she has contributed with 17 publications.

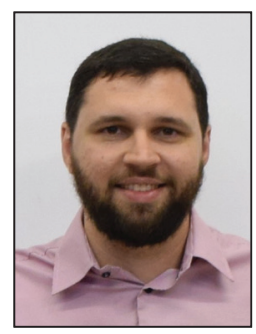

Marco A. Sperança is graduated in Chemistry in 2013 at the Universidade Federal de São Carlos (UFSCar), Brazil, where he also got his Master's degree in 2015, and his PhD degree in 2019 under the supervision of Prof Dr Edenir R. Pereira-Filho with a participation as guest researcher on Fraunhofer Institute of Lasertechnology (ILT) on Aachen, Germany, under supervision of Dr Reinhard Noll. Nowadays, he is a Post-doctoral researcher in Brazil at Instituto de Química, Campus Araraquara (IQ-Car), Universidade Estadual Paulista (UNESP). Has experience in Chemistry, focusing on analytical chemistry, acting on the following subjects: atomic absorption/emission spectrometry, X-ray fluorescence spectroscopy and chemometrics. He is author/ co-author of 19 papers published in international peerreviewed journals and has an $H$ factor of 9.

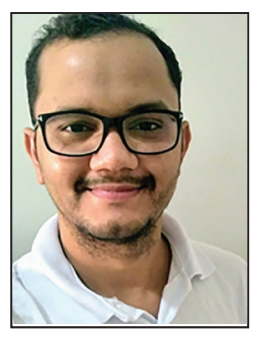

Alisson S. Araújo has a degree in Chemistry from the Universidade Federal do Sul e Sudeste do Pará (Unifesspa), where he received a scholarship from the Conselho Nacional de Desenvolvimento Científico e Tecnológico (CNPq) for two years. Currently he is master student in Analytical Chemistry at the Universidade Federal de São Carlos (UFSCar) under the supervision of Prof Edenir R. Pereira-Filho. He has experience in the area of chemistry, with emphasis on analytical chemistry, and works mainly on the following topics: development and application of chemometric tools: design of experiments, classification, multivariate and multiway calibration. The results of his studies were published in three scientific articles and two of them were from his project when he was an undergraduate student.

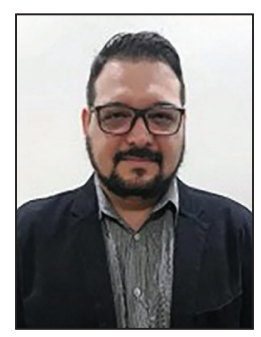

José A. Garcia is graduated in Chemistry in 2010 at the Universidade Camilo Castelo Branco (Unicastelo), Brazil. In 2014, he received Master's degree in Technological Chemistry at the Universidade Federal de São Carlos (UFSCar). Currently, he is performing a PhD degree in Analytical Chemistry at UFSCar, under the supervision of Prof Edenir R. Pereira-Filho. Garcia has over thirteen years of experience in a multi-national company in the field of $R \& D$. Last position was as Project Specialist at Fundação de Apoio a Capacitação em Tecnologias da Informação (FACTI) in Campinas-SP, where his main function was to develop chemical processes for the industry. His research interests are in the areas of chemometrics (statistical and mathematical tools for solving chemical problems, such as quality control, development of analytical methods and development of industrial processes) and in the application of spectroanalytical techniques as tools of Process Analytical Technology (PAT). He is also one of the founders of $S G$ Soluções Científicas, a spin-off from his research group.

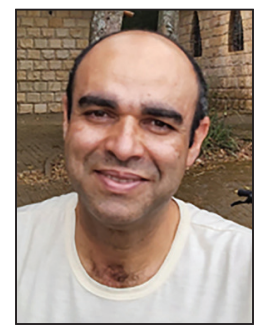

Edenir R. Pereira-Filho is Associate Professor at Federal University of São Carlos, Chemistry Department (UFSCar/DQ) since 2006. Graduated in Chemistry in 1996 at Pontifical Catholic University of Campinas (PUC-Campinas, Campinas, São Paulo State, Brazil) and obtained his PhD degree at Campinas State University (Unicamp, Campinas) in 2003. In 2001, he developed part of his PhD at the Institute of Spectrochemistry and Applied Spectroscopy, now Institute for Analytical Sciences (ISAS), Dortmund, Germany. His interests are related to do researches about LIBS (laser-induced breakdown spectroscopy), sample preparation, biological and environmental sample analyses, images (digital and hyperspectral) and chemometrics application in analytical chemistry. He published more than 100 papers involving $A A S$, slurry samples, sample preparation using microwave oven, flow analysis, spectrophotometry, LIBS and chemometrics. In addition, he is co-author of three patents: (i) use of microwave oven and flow analysis for food and biological sample preparation, (ii) closed vessel digester block sample preparation, (iii) chemical information visualization using hyperspectral images and LIBS. In 2010, he performed a post-doc project at Dalhousie University (Halifax, Canada). Up to 2020 supervised 20 and 12 master and PhD students, respectively. His 
YouTube channel has more than 800 followers (almost 400 videos) and is devoted to design of experiments (DoE) in Chemistry. He is very engaged in team work, helping and improving his students professional skills, and this review is an excellent example.

\section{References}

1. Galbacs, G.; Anal. Bioanal. Chem. 2015, 407, 7537.

2. Noll, R.; Laser-Induced Breakdown Spectroscopy: Fundamentals andApplications, 1 $^{\text {st }}$ ed.; Springer-Verlag: Berlin, Heidelberg, 2012.

3. Andrade, D. F.; Pereira-Filho, E. R.; Amarasiriwardena, D.; Appl. Spectrosc. Rev. 2020, DOI 10.1080/05704928.2020.1739063.

4. Cremers, D. A.; Radziemski, L. J.; Handbook of Laser-Induced Breakdown Spectroscopy, $2^{\text {nd }}$ ed.; John Wiley \& Sons Ltd.: Chichester, 2013.

5. Musazzi, S.; Perini, U.; Laser-Induced Breakdown Spectroscopy: Theory and Applications; Springer: Berlin, Heidelberg, 2014.

6. Pasquini, C.; Cortez, J.; Silva, L. M. C.; Gonzaga, F. B.; J. Braz. Chem. Soc. 2007, 18, 463.

7. Winefordner, J. D.; Gornushkin, I. B.; Correll, T.; Gibb, E.; Smith, B. W.; Omenetto, N.; J. Anal. At. Spectrom. 2004, 19, 1061.

8. Guezenoc, J.; Gallet-Budyne, A.; Bousquet, B.; Spectrochim. Acta, Part B 2019, 160, 105688.

9. Nicolodelli, G.; Cabral, J.; Menegatti, C. R.; Marangoni, B.; Senesi, G. S.; TrAC, Trends Anal. Chem. 2019, 115, 70.

10. El Haddad, J.; Canioni, L.; Bousquet, B.; Spectrochim. Acta, Part B 2014, 101, 171.

11. Ruan, F.; Zhang, T.; Li, H.; Appl. Spectrosc. Rev. 2019, 54, 573.

12. Gazeli, O.; Bellou, E.; Stefas, D.; Couris, S.; Food Chem. 2020, 302, 125329.

13. Figueiredo, C.; Castro, J. P.; Sperança, M. A.; Fialho, L. L.; Nóbrega, J. A.; Pereira-Filho, E. R.; J. Braz. Chem. Soc. 2018, 29,680 .

14. Jolivet, L.; Leprince, M.; Moncayo, S.; Sorbier, L.; Lienemann, P.; Motto-Ros, V.; Spectrochim. Acta, Part B 2019, 151, 41.

15. Noll, R.; Fricke-Begemann, C.; Connemann, S.; Meinhardt, C.; Sturm, V.; J. Anal. At. Spectrom. 2018, 33, 945.

16. Rezaei, F.; Cristoforetti, G.; Tognoni, E.; Leganaioli, S.; Palleschi, V.; Safi, A.; Spectrochim. Acta, Part B 2020, 169, 105878.

17. Moros, J.; Laserna, J.; Appl. Spectrosc. 2019, 73, 963.

18. Santos, D.; Nunes, L. D.; Carvalho, G. G. A.; Gomes, M. S.; Souza, P. F.; Leme, F. O.; Santos, L. G. C.; Krug, F. J.; Spectrochim. Acta, Part B 2012, 71-72, 3.

19. Senesi, G. S.; Martin-Neto, L.; Villas-Boas, P. R.; Nicolodelli, G.; Milori, D. M. B. P.; J. Soils Sediments 2018, 18, 1292.

20. Costa, V. C.; Augusto, A. S.; Castro, J. P.; Machado, R. C.; Andrade, D. F.; Babos, D. V.; Sperança, M. A.; Gamela, R. R.; Pereira-Filho, E. R.; Quim. Nova 2019, 42, 527.
21. Machado, R. C.; Andrade, D. F.; Babos, D. V.; Castro, J. P.; Costa, V. C.; Sperança, M. A.; Garcia, J. A.; Gamela, R. R.; Pereira-Filho, E. R.; J. Anal. At. Spectrom. 2020, 35, 54.

22. Miziolek, A. W.; Palleschi, V.; Schechter, I.; Laser-Induced Breakdown Spectroscopy (LIBS): Fundamentals and Applications; Cambridge University Press: Cambridge, 2006.

23. Liu, K.; Liu, C.; Li, Y.; Yang, G.; Ding, Y.; TrAC, Trends Anal. Chem. 2019, 110, 327.

24. Rehse, S. J.; Spectrochim. Acta, Part B 2019, 154, 50.

25. Nespeca, M. G.; Vieira, A. L.; Santos, D.; Neto, J. A. G.; Ferreira, E. C.; Food Chem. 2020, 311, 125886.

26. Dibia, S.; Nespeca, M. G.; Santos, D.; Ribeiro, C. A.; Neto, J. A. G.; Ferreira, E. C.; Microchem. J. 2020, 157, 105107.

27. Almessiere, M. A.; Altuwiriqi, R.; Gondal, M. A.; AlDakheel, R. K.; Alotaibi, H. F.; Talanta 2018, 185, 61.

28. Ruiz, F. J.; Ripoll, L.; Hidalgo, M.; Canais, A.; Talanta 2019 , $191,162$.

29. Babos, D. V.; Virgílio, A.; Costa, V. C.; Donati, G. L.; PereiraFilho, E. R.; J. Anal. At. Spectrom. 2018, 33, 1753.

30. Babos, D. V.; Barros, A. I.; Nóbrega, J. A.; Pereira-Filho, E. R.; Spectrochim. Acta, Part B 2019, 155, 90.

31. Hao, Z. Q.; Liu, L.; Zhou, R.; Ma, Y. W.; Li, X. Y.; Guo, L. B.; Lu, Y. F.; Zeng, X. Y.; Opt. Express 2018, 26, 22926.

32. Nunes, L. C.; Rocha, F. R. P.; Krug, F. J.; J. Anal. At. Spectrom. 2019, 34, 2314.

33. Castro, J. P.; Babos, D. V.; Pereira-Filho, E. R.; Talanta 2020, 208, 120443.

34. Yuan, R.; Tang, Y.; Zhu, Z.; Hao, Z.; Li, J.; Yu, H.; Yu, Y.; Guo, L.; Zeng, X.; Lu, Y.; Anal. Chim. Acta 2019, 1064, 11.

35. Zhang, T.; Tang, H.; Li, H.; J. Chemom. 2018, 32, 2983.

36. Hahn, D. W.; Omenetto, N.; Appl. Spectrosc. 2010, 64, 335.

37. Lepore, K. H.; Fassett, C. I.; Breves, E. A.; Byrne, S.; Giguere, S.; Boucher, T.; Rhodes, J. M.; Vollinger, M.; Anderson, C. H.; Murray, R. W.; Dyar, M. D.; Appl. Spectrosc. 2017, 71, 600.

38. Takahashi, T.; Thornton, B.; Spectrochim. Acta, Part B 2017, $138,31$.

39. Hahn, D. W.; Omenetto, N.; Appl. Spectrosc. 2012, 66, 347.

40. Popov, A. M.; Zaytsev, S. M.; Seliverstova, I. V.; Zakuskin, A. S.; Labutin, T. A.; Spectrochim. Acta, Part B 2018, 148, 205.

41. Morais, C.; Barros, A. I.; Bechlin, M. A.; Silva, T. V.; Santos Jr., D.; Senesi, G. S.; Crespi, M. S.; Ribeiro, C. A.; Gomes Neto, J. A.; Ferreira, E. C.; Talanta 2018, 188, 199.

42. Colgan, J.; Barefield, J. E.; Judge, E. J.; Campbell, K.; Johns, H. M.; Kilcrease, D. P.; McInroy, R.; Clegg, S. M.; Spectrochim. Acta, Part B 2016, 122, 85.

43. Carter, J. A.; Barros, A. I.; Nóbrega, J. A.; Donati, G. L.; Front. Chem. 2018, 6, 504.

44. Vieira, A. L.; Silva, T. V.; Souza, F. S. I.; Senesi, G. S.; Santos Jr., D.; Ferreira, E. C.; Gomes Neto, J. A.; Microchem. J. 2018, 139, 322.

45. Costa, V. C.; Babos, D. V.; Aquino, F. W. B.; Virgílio, A.; Amorim, F. A. C.; Pereira-Filho, E. R.; Food Anal. Methods 2018, 11, 1886. 
46. Andrade, D. F.; Pereira-Filho, E. R.; Konieczynski, P.; J. Braz. Chem. Soc. 2017, 28, 838.

47. Marangoni, B. S.; Silva, K. S. G.; Nicolodelli, G.; Senesi, G. S.; Cabral, J. S.; Villas-Boas, P. R.; Silva, C. S.; Teixeira, P. C.; Nogueira, A. R. A.; Benites, V. M.; Milori, D. M. B. P.; Anal. Methods 2016, 8, 78.

48. Castro, J. P.; Pereira-Filho, E. R.; J. Anal. At. Spectrom. 2016, 31, 2005.

49. Moncayo, S.; Manzoor, S.; Rosales, J. D.; Anzano, J.; Caceres, J. O.; Food Chem. 2018, 244, 324.

50. Peruchi, L. C.; Nunes, L. C.; Carvalho, G. G. A.; Guerra, M. B. B.; Almeida, E.; Rufini, I. A.; Santos Jr., D.; Krug, F. J.; Spectrochim. Acta, Part B 2014, 100, 129.

51. Ranulfi, A. C.; Senesi, G. S.; Caetano, J. B.; Meyer, M. C.; Magalhães, A. B.; Villas-Boas, P. R.; Milori, D. M. B. P.; Microchem. J. 2018, 141, 118.

52. Donati, G. L.; Amais, R. S.; J. Anal. At. Spectrom. 2019, 34, 2353.

53. Morais, C.; Barros, A. I.; Santos Jr., D.; Ribeiro, C. A.; Crespi, M. S.; Senesi, G. S.; Gomes Neto, J. A.; Ferreira, E. C.; Microchem. J. 2018, 134, 370.

54. Aquino, F. W. B.; Paranhos, C. M.; Pereira-Filho, E. R.; J. Anal. At. Spectrom. 2016, 31, 1228.

55. Carvalho, A. A. C.; Leme, F. O.; Luz, M. S.; Oliveira, P. V.; Nomura, C. S.; J. Anal. At. Spectrom. 2018, 33, 1243.

56. Sperança, M. A.; Pomares-Alfonso, M. S.; Pereira-Filho, E. R.; Anal. Methods 2018, 10, 533.

57. Bilge, G.; Boyaci, I. H.; Eseller, K. E.; Tamer, U.; Çakir, S.; Food Chem. 2015, 181, 186.

58. Tian, Y.; Cheung, H. C.; Zheng, R.; Ma, Q.; Chen, Y.; DelepineGilon, N.; Yu, J.; Spectrochim. Acta, Part B 2016, 124, 16.

59. Wang, J.; Shi, M.; Zheng, P.; Xue, S.; J. Appl. Spectrosc. 2017, $84,188$.

60. Singh, J.; Kumar, R.; Awasthi, S.; Singh, V.; Rai, A. K.; Food Chem. 2017, 221, 1778.

61. Virgílio, A.; Gonçalves, D. A.; McSweeney, T.; Gomes Neto, J. A.; Nóbrega, J. A.; Donati, G. L.; Anal. Chim. Acta 2017, 982, 31.

62. Machado, R. C.; Silva, A. B. S.; Donati, G. L.; Nogueira, A. R. A.; J. Anal. At. Spectrom. 2018, 33, 1168.

63. Augusto, A. S.; Castro, J. P.; Sperança, M. A.; Pereira-Filho, E. R.; J. Braz. Chem. Soc. 2019, 30, 804.

64. Fortunato, F. M.; Catelani, T. A.; Pomares-Alfonso, M. S.; Pereira-Filho, E. R.; Anal. Sci. 2019, 35, 165.

65. Andrade, D. F.; Fortunato, F. M.; Pereira-Filho, E. R.; Anal. Chim. Acta 2019, 1061, 42.

66. Carvalho, A. A. C.; Cozer, L. A.; Luz, M. S.; Nunes, L. C.; Rocha, F. R. P.; Nomura, C. S.; J. Anal. At. Spectrom. 2019, 34, 1701.

67. Bader, M. A.; J. Chem. Educ. 1980, 57, 703.

68. Kelly, W. R.; MacDonald, B. S.; Guthrie, W. F.; Anal. Chem. 2008, 80, 6154.

69. Costa, V. C.; Pinheiro, F. C.; Silva, E. P. G.; Pereira-Filho, E. R.; Microchem. J. 2019, 150, 104.
70. Gamela, R. R.; Costa, V. C.; Babos, D. V.; Araujo, A. S.; PereiraFilho, E. R.; Food Anal. Methods 2020, 13, 1017.

71. Pinheiro, F. C.; Barros, A. I.; Nóbrega, J. A.; Microchem. J. 2019, 146, 948.

72. Kumar, N.; Bansal, A.; Sarma, G. S.; Rawal, R. K.; Talanta 2014, 123, 186.

73. Pimentel, M. F.; Barros-Neto, B.; Quim. Nova 1996, 19, 268.

74. Passari, L. M. Z. G.; Soares, P. K.; Bruns, R. E.; Scarminio, I. S.; Quim. Nova 2011, 34, 888.

75. Bro, R.; Anal. Chim. Acta 2003, 500, 185.

76. Ferreira, M. M. C.; Antunes, A. M.; Melgo, M. S.; Volpe, P. L. O.; Quim. Nova 1999, 22, 724.

77. Brereton, R. G.; Analyst 2000, 125, 2125.

78. Sha, W.; Li, J.-t.; Lu, C.-p.; Zhen, C.-h.; Spectrosc. Spectral Anal. 2019, 39, 1958.

79. Gamela, R. R.; Costa, V. C.; Sperança, M. A.; Pereira-Filho, E. R.; Food Res. Int. 2020, 132, 109037.

80. Sperança, M. A.; Andrade, D. F.; Castro, J. P.; Pereira-Filho, E. R.; Opt. Laser Technol. 2019, 109, 648.

81. Yaroshchyk, P.; Death, D. L.; Spencer, S. J.; J. Anal. At. Spectrom. 2012, 27, 92.

82. Guo, G.; Niu, G.; Shi, Q.; Lin, Q.; Tian, D.; Duan, Y.; Anal. Methods 2019, 11, 3006.

83. Ding, Y.; Xia, G.; Ji, H.; Xiong, X.; Anal. Methods 2019, 11, 3657.

84. Lu, C.; Wang, B.; Jiang, X.; Zhang, J.; Niu, K.; Yuan, Y.; Plasma Sci. Technol. 2019, 21, 034014.

85. El Haddad, J.; Villot-kadri, M.; Ismael, A.; Gallou, G.; Michel, K.; Bruyere, D.; Laperche, V.; Canioni, L.; Bousquet, B.; Spectrochim. Acta, Part B 2013, 79-80, 51.

86. Ayyalasomayajula, K. K.; Yu-Yueh, F.; Singh, J. P.; McIntyre, D. L.; Jain, J.; Appl. Opt. 2012, 51, B149.

87. Devangad, P.; Unnikrishnan, V. K.; Tamboli, M. M.; Shameem, K. M. M.; Nayak, R.; Choudhari, K. S.; Santhosh, C.; Anal. Methods 2016, 8, 7184.

88. Takahashi, T.; Thornton, B.; Sato, T.; Ohki, T.; Ohki, K.; Sakka, T.; Spectrochim. Acta, Part B 2016, 124, 87.

89. Costa, V. C.; Aquino, F. W. B.; Paranhos, C. M.; Pereira-Filho, E. R.; Waste Manage. 2017, 70, 212.

90. Goueguel, C. L.; Soumare, A.; Nault, C.; Nault, J.; J. Anal. At. Spectrom. 2019, 34, 1588.

91. Ferreira, E. C.; Milori, D. M. B. P.; Ferreira, E. J.; da Silva, R. M.; Martin-Neto, L.; Spectrochim. Acta, Part B 2008, 63, 1216.

92. Bhatt, B.; Angeyo, K. H.; Dehayem-Kamadjeu, A.; Anal. Methods 2018, 10, 791.

93. Inakollu, P.; Philip, T.; Rai, A. K.; Yueh, F. Y.; Singh, J. P.; Spectrochim. Acta, Part B 2009, 64, 9.

Submitted: May 1, 2020

Published online: August 28, 2020 